ARTÍCULO ORIGINAL

\title{
Intervalos de referencia de minerales en cerdos confinados de diferentes genéticas y categorías
}

\author{
Luna $\mathrm{ML}^{1 *}$, Roldan $\mathrm{VP}^{1}$, Campa $\mathrm{M}^{2}$, Manni $\mathrm{D}^{3}$, Bellezze $\mathrm{J}^{1}$, Agosto, $\mathrm{M}^{2}$ \\ ${ }^{1}$ Cátedra de Química I y II, Facultad de Ciencias Veterinarias - Universidad Nacional del Litoral \\ (FCV-UNL), Esperanza, Santa Fe, Argentina. \\ ${ }^{2}$ Cátedra de Producción de Cerdos, FCV-UNL, Esperanza, Santa Fe, Argentina. \\ ${ }^{3}$ Departamento de Matemática, Facultad de Bioquímica y Ciencias Biológicas - Universidad \\ Nacional del Litoral (FBCB-UNL), Santa Fe, Argentina
}

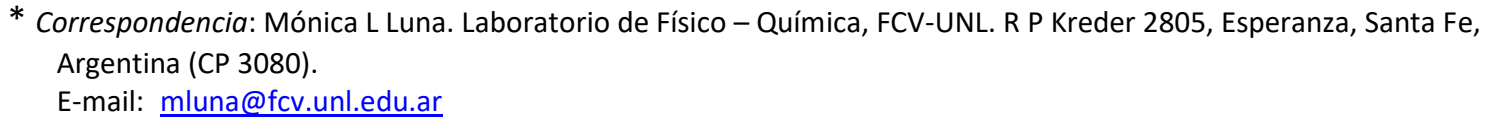

RESUMEN. En Argentina, no existen datos regionales de intervalos de referencia de minerales en cerdos según las líneas genéticas actuales y distintas categorías de producción en sistema intensivo. Por ello, el objetivo del presente estudio fue determinar intervalos de minerales: calcio, fósforo, magnesio, sodio, potasio, hierro, cobre y cinc, en suero de cerdos en establecimientos del centro de Santa Fe y de Entre Ríos. Se trabajó con 300 muestras de sangre de cerdos sanos de dos líneas genéticas diferentes en las categorías de lechones recién nacidos, lechones destetados, hembras nulíparas gestantes seleccionadas fenotípicamente para la reposición del plantel, y hembras multíparas gestantes. Se determinaron las concentraciones séricas de los minerales por espectrofotometría de absorción atómica (FAAS) con un equipo Perkin Elmer modelo Analys 200, con métodos oficiales de AOAC. Se analizaron también muestras de agua. Los intervalos de referencia se calcularon utilizando parámetros paramétricos o no paramétricos dependiendo de la distribución de los datos. Los valores medios, medianas, valores mínimo y máximo e intervalos de referencia, para los distintos minerales en cada categoría productiva, se presentan en tablas. Los intervalos de referencia calculados serán útiles para el diagnóstico de deficiencias mineral y la vigilancia nutricional en cerdo de producción de carne.

SUMMARY. Mineral reference intervals in confined swine with different genetic background and categories. In Argentina, there is no regional data on mineral reference intervals in swine, according to the genetic lines, categories of production in intensive systems. The objective of this study was to establish ranges of the following serum minerals: calcium, phosphorus, magnesium, sodium, potassium, iron, copper and zinc, in swine farmed in Santa Fe and Entre Ríos. Blood samples were collected from 300 healthy pigs of two different genetic lines belonging to the following categories: newborn piglets, weaned piglets, pregnant nulliparous females selected for re-stocking, and pregnant multiparous females. Serum concentrations of minerals were determined by atomic absorption spectrophotometry (FAAS) with a Perkin Elmer model Analys 200 and using official AOAC methods. Water samples were also analyzed. Reference intervals were calculated using parametric or nonparametric methods on basis of data distribution. Mean, median, minimum, maximum values and reference intervals for different minerals were tabulated. The reference intervals calculated in this study will be useful for the diagnosis of mineral deficiencies and nutritional monitoring in meat production pigs.

Palabras clave: porcinos, minerales, etapas productivas, líneas genéticas, Argentina

Key words: swine, minerales, production stages, genetic lines, Argentina

\section{Introducción}

En Argentina, los sistemas de producción de cerdos utilizados en las granjas han cambiado a lo largo de las dos últimas décadas. Los establecimientos de producción son más grandes y el manejo más intensivo lo que implica cambios en la nutrición e infraestructura (FAO 2013; García, 2006).

Debido a la introducción de nuevas líneas de cerdas maternas capaces de producir camadas más numerosas, con mayor peso de nacimiento, y más producción de leche, se obtienen más lechones destetados y de mayor peso, lo cual hace excesivamente alta la demanda nutricional (Mahan, 2006). Al igual que con la alimentación, el sistema de tipificación en Argentina ha 
impulsado al productor a cambiar sus animales de genética heterogénea, por otros provenientes de empresas de alto mérito genético, tanto de origen nacional (INTA, MGC) como extranjeras (DEGESA; PIC; etc.) (Campagna, 2005).

Con respecto a la alimentación, ésta debe ser suficiente y adecuada para satisfacer los requerimientos nutricionales y prevenir patologías, tendiendo así a lograr un sistema productivo óptimo (Crenshaw et al., 2013). En este sentido, por ejemplo, durante los últimos 14 días de gestación, aproximadamente el $50 \%$ de los minerales totales ingeridos son retenidos en el cuerpo para el desarrollo fetal. Asimismo, durante la lactancia la retención de minerales es mayor que en la gestación tardía y aumenta a medida que crece el tamaño de la camada. En efecto, la última fase de gestación y lactancia son las etapas críticas y de mayor demanda de minerales para la cerda. Por otro lado, la composición mineral de la leche en la cerda se debe en gran parte al control genético y se ve influida por la etapa de lactancia, y el tamaño de la camada (Mahan, 2006).

Todos los tejidos animales contienen elementos minerales (Muñiz et al., 2005). En la actualidad se conoce la existencia de 60 minerales en los suelos, siendo en base a las necesidades de mantenimiento y producción (crecimiento, sanidad y reproducción), 30 de ellos esenciales para los animales. Estos minerales se clasifican en cuatro grupos: Grupo 1, Macrominerales esenciales, son 7: se encuentran en las dietas por encima de los $100 \mathrm{ppm}$ y se expresan en $\mathrm{g} / \mathrm{kg}$ o tanto por cien (\%) y ellos son: calcio (Ca), fósforo $(\mathrm{P})$, cloro $(\mathrm{Cl})$, magnesio $(\mathrm{Mg})$, potasio $(\mathrm{K})$, sodio $(\mathrm{Na})$, azufre $(\mathrm{S})$; Grupo 2, Microminerales esenciales, son 9: se encuentran en las dietas por debajo de los 100 ppm y se expresan en $\mathrm{mg} / \mathrm{kg}$ o ppm; a saber: cobre (Cu), cobalto (Co), cromo (Cr), hierro (Fe), iodo (I), manganeso (Mn), molibdeno (Mo), selenio (Se) y cinc (Zn); Grupo 3, Minerales esenciales menores, en total 11 , son beneficiosos en determinadas circunstancias, y son bien conocidos por su toxicidad. Se expresan en $\mathrm{mg} / \mathrm{kg}$ o ppb $(\mu \mathrm{g} / \mathrm{kg})$. Aluminio (Al), arsénico (As), boro (B), bromo $(\mathrm{Br})$, estaño $(\mathrm{Sn})$, fluor $(\mathrm{F})$, litio $(\mathrm{Li})$, niquel $(\mathrm{Ni})$, rubidio $(\mathrm{Rb})$, silicio $(\mathrm{Si})$, vanadio $(\mathrm{V})$; Grupo 4 , Minerales altamente tóxicos no esenciales, sólo 3: cadmio (Cd), mercurio $(\mathrm{Hg})$ y plomo $(\mathrm{Pb})$. Se expresan en $\mathrm{mg} / \mathrm{kg} 0$ $\mathrm{ppb}(\mu \mathrm{g} / \mathrm{kg})$ (Yague, 2007).

Los minerales son ingeridos a través de los alimentos y el agua; a pesar de ello, no todos se encuentran biodisponibles (NRC, 2012). El agua de bebida, nutriente básico para la producción porcina; debe ser potable, fácilmente disponible y no contener sustancias nocivas. García González (2009) manifiesta que se debería tener en cuenta el aporte de minerales a través del agua a la hora de formular la dieta. Durante la digestión, la manera en que se dispone del mineral a nivel interno, determinará su utilización y absorción a nivel sanguíneo. Asimismo, la cantidad de minerales absorbida a nivel digestivo también dependerá de la edad del cerdo, la etapa de producción, el consumo en base a requerimientos, la forma química, la dieta y de factores ambientales. Además, los minerales pueden interaccionar con uno o varios elementos, sinergismos y antagonismos, lo que influye en sus propios requerimientos y con los otros minerales (Cooper et al., 2014).

Todo esto demuestra la importancia de una buena nutrición en lo que respecta al aporte de minerales para lograr una producción rentable de cerdos. Al igual que para otras especies, en los suinos los intervalos de referencia pueden variar con el sexo, el medio ambiente, la actividad física y el estrés (Cooper et al., 2014; Klem, 2010). Sin embargo, en Argentina no existe en la literatura intervalos de minerales de referencia para cerdos.

Como consecuencia de lo expresado anteriormente y debido a la falta de datos regionales, el objetivo del presente trabajo consistió en determinar los intervalos de referencia de los minerales calcio, fósforo, magnesio, sodio, potasio, hierro, cobre y cinc en suero de cerdos de diferentes genéticas y etapas productiva en sistemas intensivos de establecimientos de la región centro de Santa Fe y de Entre Ríos de la República Argentina.

En el estudio, se tomaron muestras de agua para evaluar su calidad y, se consideraron los parámetros de agua potable para consumo humano y animal (Spiner, 2009).

En cuanto a los alimentos que forman parte de la dieta, el manejo se realizó en base a las fórmulas $y$ requerimientos necesarios para cada categoría de cerdos en producción. El análisis de la composición química mineral de los mismos queda sujeta un nuevo proyecto en curso, que estudia distintas fuentes minerales.

\section{Materiales y Métodos}

\section{Establecimientos}

Se trabajó con dos establecimientos intensivos, con piso slat plástico sin acceso a tierra y reposición de reproductores de forma externa. Una de ellas se localiza en el centro de la provincia de Santa Fe, departamento Belgrano, a $12 \mathrm{~km}$ al sur-oeste de la localidad de Centeno, donde se encuentran las categorías de reproductores y lechones hasta las 12 13 semanas de edad. Luego se trasladó a los animales al sitio de engorde y terminación, a una distancia de 5 $\mathrm{km}$ del anterior. La otra granja está ubicada en la localidad de Molino Doll en la Provincia de Entre Ríos, en donde se llevan a cabo la reproducción, cría, recría y terminación de los animales. 
Los animales recién nacidos fueron alimentados con leche materna, siendo el resto, alimentados con una dieta balanceada en base a maíz y expeler de soja elaborada en los establecimientos.

Las dietas de cada categoría, a partir del destete, fueron balanceadas y formuladas según los requerimientos de minerales y demás nutrientes especificados por la NRC (2012).

\section{Animales}

Las muestras de sangre fueron extraídas de cerdos sanos de dos líneas genéticas diferentes, pertenecientes a establecimientos intensivos de las provincias de Santa Fe (genética A) y Entre Ríos (genética B) de Argentina. Ambas líneas genéticas comerciales están bien definidas y son el resultado del cruzamiento de animales de las razas Yorkshire, Landrance y Pietrain. Los establecimientos cumplen con las normas sanitarias obligatorias exigidas por SENASA, y se realizó vigilancia epidemiológica de las lesiones en frigorífico y en necropsias dentro de los establecimientos.

\section{Etapas productivas}

Las categorías que se estudiaron fueron lechones recién nacidos (RN), lechones destetados (D), hembras nulíparas gestantes de genética definida empleadas para la reposición del plantel, denominadas 'cachorras' $(\mathrm{CH})$, y hembras multíparas gestantes (G) de segundo a cuarto parto. El destete o desleche se realizó de los 21 a los 28 días de edad de los lechones, con pesos de 6 a $7,5 \mathrm{~kg}$. La reposición del plantel de hembras se realizó en forma externa con cachorras de 20 a 30 semanas de edad provenientes de cada una de las líneas genéticas comerciales. Los animales se seleccionaron al azar y fueron sometidos a un control clínico antes de extraer las muestras de sangre para descartar los individuos que presenten signos de enfermedad.

\section{Muestra de sangre}

Se extrajeron 300 muestras de sangre de la vena yugular de las cerdas gestantes con agujas $50 \times 1,2 \mathrm{~mm}$ y de la vena cava de los lechones con agujas $25 \times 0,9$ $\mathrm{mm}$, colectándose en tubos de ensayo sin anticoagulante para la determinación serológica de minerales.

Los sueros libres de hemólisis se separaron de la sangre entera por centrifugación a $6000 \mathrm{G}$, dentro de las dos horas posteriores de tomada la muestra. Luego, se transportaron en nevera portátil con hielo seco dentro de las 8 horas posteriores a su recolección al laboratorio de Química de la Facultad de Ciencias Veterinarias de la Universidad Nacional del Litoral. Para la conservación de los sueros se almacenaron a $-20^{\circ} \mathrm{C}$ hasta el momento de dosaje de los minerales.

\section{Muestras de Agua}

Las muestras de agua fueron tomadas de los bebederos, transportadas en conservadora refrigerada para análisis fisicoquímico y bacteriológico de potabilidad del agua. Los niveles de sulfatos en el agua de bebida se determinaron por turbidimetría. Para la determinación de los parámetros del agua, se aplicaron los métodos descriptos por Association of Official Analytical Chemist (AOAC, 2005). Todas las mediciones se hicieron por triplicado y se consideró el valor promedio en cada una de las determinaciones.

\section{Eritrocitos no sensibilizados de conejo (ERC)}

El día del ensayo, se obtuvo de un conejo (Oryctogalus cuniculus) un volumen de $5 \mathrm{~mL}$ de sangre venosa. La sangre fue trasvasada dentro de un tubo heparinizado y este para su conservación fue refrigerado durante un período no mayor a una hora. Posteriormente, la sangre fue centrifugada a $1500 \mathrm{~g}$ durante $10 \mathrm{~min} y$ posteriormente se registró el volumen total de la muestra y el volumen total del paquete de células sanguíneas. Posteriormente, el plasma fue descartado y el paquete celular fue lavado y suspendido con una solución fría de buffer salino monofosfato 0,01 M (PSB) con $\mathrm{pH} 7,4$. Este procedimiento se repitió cuatro veces antes de realizar la centrifugación final. Luego de descartar el sobrenadante, se realizaron diluciones seriadas hasta lograr que la concentración de eritrocitos fuera del $2 \%$ respecto del volumen inicial del paquete celular.

\section{Métodos analíticos}

Las concentraciones séricas de calcio, fósforo, magnesio, sodio, potasio, hierro, cobre y cinc se determinaron por espectrofotometría de absorción atómica (FAAS) con un equipo Perkin Elmer modelo Analys 200 en el laboratorio central de la Facultad de Ciencias Agrarias de la Universidad Nacional del Litoral. Para la destrucción de la materia orgánica se calentó $1 \mathrm{~mL}$ de suero en una plancha calefactora a $90{ }^{\circ} \mathrm{C}$ con $5 \mathrm{~mL}$ de ácido nítrico concentrado durante 2 horas, aproximadamente.

Los minerales se determinaron respetando las técnicas propuestas por la AOAC (Association of Official Analytical Chemist, 2005). En los casos en que la muestra recibió algún tratamiento específico para la determinación de un mineral, los estándares también fueron sometidos al mismo proceso. En todos los casos se utilizaron reactivos de calidad p.a. y estándares con los que se efectuaron las calibraciones. Cada muestra se procesó por duplicado y los valores $\leq 5 \%$ fueron promediados, para esto se replicaron las pruebas hasta obtener valores promediables. Todas las determinaciones fueron validadas y controladas periódicamente con material de referencia certificado.

Para cada mineral a determinar se trabajó en condiciones estándar y con blancos de cada reactivo. Fueron 
realizadas curvas de calibración (concentración versus absorbancia).

\section{Análisis estadístico}

Los valores atípicos fueron identificados y se eliminaron de la base de datos previo al análisis estadístico. Los Intervalos de referencia para tales variables se calcularon como la media de la muestra $\pm 1,96$ desviaciones estándar. Se comprobó la normalidad de las variables por medio del test de Shapiro-Wilk con una significancia de $5 \%$. Para las variables que no presentaron distribución normal, se calculó el logaritmo decimal y posteriormente fueron analizadas para normalidad con el test de Kolmogorovs. Aquellas variables que no poseían distribución normal incluso luego de la transformación se trabajaron de forma no paramétrica calculando los percentiles 2,5 y 97,5 .

\section{Resultados}

Un total de 300 muestras de sangre fueron analizadas dentro del perfil mineral. Los valores medios, desvío estándar, medianas, valores mínimo y máximo e intervalos de referencia para los distintos minerales en cada categoría y para las dos líneas genéticas, se presentan en la Tabla 1a para cachorras ( $\mathrm{CH}$ ) y ges-tantes (G), y en la Tabla $1 \mathrm{~b}$ para los animales recién nacidos ( $\mathrm{RN}$ ) y destetados (D).

Los resultados de los valores medios para el agua, fueron: cloruro (mg/L) 420 - 118; sulfato (mg/L) 763,5 - 490; nitrato (mg/L) 30,5 - 9,0; nitritos (mg/L) 0,06 $<0,02$; fluoruros (mg/L) $1,19-0,88$; amonio $(\mathrm{mg} / \mathrm{L})$ $<0,05-<0,05$; arsénico (mg/L) 0,05 - <0,01; Hierro (mg/L) 0,055-0,030; calcio (mg/L) $64-121$; magnesio (mg/L) 47 - 9; sodio (mg/L) 645 - 210; dureza total (mg/L) 254 - 337; alcalinidad total (mg/L) $445-330 ; \mathrm{pH}$ 7,77 - 7,61; y conductividad (US/cm) 3085 - 1430; en las granjas con genética $A-B$, respectivamente. En el análisis bacteriológico el recuento de las bacterias aeróbicas en la genética $A$ fue de 72 y de 90 bacterias por $\mathrm{mL}$, en las muestras tomadas de las granjas de genética A y B respectivamente, coliformes $<2,2$ $\mathrm{NMP} / 100 \mathrm{~mL}$ y ausencia de Pseudomonas auruginosa en $100 \mathrm{~mL}$.

\section{Discusión}

Los parámetros de macrominerales y microminerales se ven afectados por una variedad de factores incluyendo edad, sexo, raza, genética, nutrición, estado de salud, medio ambiente y estrés (Cooper et al., 2014; Klem, 2010). Al evaluar los resultados, esos factores deben ser considerados para lograr una buena interpretación de los minerales obtenidos.
Analizamos en cada categoría los valores medios entre las dos líneas genéticas y observamos:

En la categoría recién nacidos, si bien los valores medios de las variables calcio, fósforo, sodio, potasio y cinc; eran normales en la línea genética $B$ eran mayores. Los valores medios más altos en la genética $B$; a excepción de hierro y cobre en el RN se podría atribuir a la cruza de animales y al manejo de los mismos (Cooper et al., 2014; Mahan, 2006).

En lechones destetados, los promedios de los minerales analizados fueron mayores en animales de genética $B$. Los intervalos de referencia de magnesio, sodio, potasio, hierro, cobre y cinc reflejaron diferencias entre las dos líneas genéticas analizadas. El valor medio del hierro sérico de lechones destetados fue descripto como un valor normal por otros investigadores (Muñiz, et al., 2005).

En la categoría gestante, los valores medios de los parámetros calcio, fósforo, magnesio, potasio, cobre y cinc fueron más bajos en genética $\mathrm{A}$. El fósforo presenta intervalo de referencia calculado diferente entre A y B. Los cambios observados en las líneas genéticas, con valores medios más altos de hierro y sodio en cerdas $\mathrm{G}$ con genética $\mathrm{B}$, se podría atribuir a la diferente cruza, manejo y nutrición de los animales (Cooper et al., 2014; Mahan, 2006).

Con respecto a las cachorras, las medias de los minerales calcio, fósforo, potasio, hierro y cinc fueron menores en los establecimientos de líneas $A$. En los minerales magnesio, sodio y cobre se observaron valores promedios iguales en las dos líneas genéticas. Los intervalos de los minerales fósforo, magnesio e hierro fueron diferente y mayores en la categoría $\mathrm{CH}$ de ambas genéticas (Muñiz et al., 2005).

Si consideramos la categoría recién nacidos, los intervalos de referencia del calcio, fósforo, magnesio y potasio presentaron diferencias entre la genética $A$ y $B$. En los animales destetados, al comparar nuestros resultados con los descriptos por otros investigadores en el día cero de ensayo, observamos que los valores medios en Fe eran mayores, siendo superiores en la línea B, y que los valores promedios de cobre se encuentran por debajo del dosado en aquel ensayo, $y$ además nuestro valor promedio de cinc eran menor en las dos líneas genéticas. Destacamos que en esa publicación trabajaron con animales de 35 días de la cruza Duroc x Landrace x Large White (Peng et al., 2016). Con la misma raza y categoría de animales trabajaron en China, y se observaron que sus valores medios de $\mathrm{Zn}, \mathrm{Ca}$, $\mathrm{K}$ se encontraban dentro del intervalo de referencia calculado en ésta publicación para la genética A y B (Duan et al., 2013). 
Tabla 1a: Medias, medianas, valores mínimo y máximo, intervalos de referencia, y distribuciones de datos para los distintos minerales en suero para la categoría recién nacidos (RN) y destetados (D)..

\begin{tabular}{|c|c|c|c|c|c|}
\hline \multirow{3}{*}{ MINERALES } & \multicolumn{5}{|l|}{ Líneas genéticas } \\
\hline & \multirow{2}{*}{ Parámetros y categoría } & \multicolumn{2}{|c|}{$\mathbf{A}$} & \multicolumn{2}{|r|}{ B } \\
\hline & & $\mathrm{RN}$ & $\mathrm{D}$ & $\mathrm{RN}$ & D \\
\hline \multirow{7}{*}{$\begin{array}{l}\text { Calcio } \\
\text { (mg/dL) }\end{array}$} & $\mathrm{n}$ & 39 & 39 & 38 & 37 \\
\hline & media & 10,37 & 9,47 & 10,70 & 10,62 \\
\hline & desvío estándar & 1,89 & 1,61 & 1,24 & 0,84 \\
\hline & mediana & 10,36 & 9,16 & 10,74 & 10,53 \\
\hline & mínimo & 6,86 & 6,83 & 8,36 & 8,58 \\
\hline & máximo & 13,80 & 12,75 & 13,32 & 12,71 \\
\hline & intervalo de referencia* & $6,66-14,07$ & $3,31-12,65$ & $8,26-13,13$ & $8,97-12,26$ \\
\hline \multirow{7}{*}{$\begin{array}{l}\text { Fósforo } \\
\text { (mg/dL) }\end{array}$} & $\mathrm{n}$ & 39 & 37 & 39 & 41 \\
\hline & media & 8,78 & 8,3 & 9,43 & 8,73 \\
\hline & desvío estándar & 1,19 & 0,92 & 1,68 & 1,20 \\
\hline & mediana & 8,75 & 8,17 & 8,78 & 8,57 \\
\hline & mínimo & 6,72 & 6,73 & 7,15 & 6,59 \\
\hline & máximo & 11,81 & 10,40 & 12,91 & 10,98 \\
\hline & intervalo de referencia* & $6,44-11,11$ & $6,49-10,10$ & $7,29-12,56$ & $6,37-11,08$ \\
\hline \multirow{7}{*}{$\begin{array}{l}\text { Magnesio } \\
\text { (mg/dL) }\end{array}$} & $\mathrm{n}$ & 39 & 39 & 39 & 41 \\
\hline & media & 2,14 & 1,83 & 1,99 & 1,95 \\
\hline & desvío estándar & 0,50 & 0,41 & 0,56 & 0,54 \\
\hline & mediana & 2,06 & 1,83 & 1,87 & 1,99 \\
\hline & mínimo & 1,35 & 0,99 & 1,24 & 1,11 \\
\hline & máximo & 3,27 & 2,74 & 3,21 & 3,04 \\
\hline & intervalo de referencia* & $1,16-3,12$ & $1,02-2,60$ & $0,89-3,08$ & $0,89-3,01$ \\
\hline \multirow{7}{*}{$\begin{array}{l}\text { Sodio } \\
\text { (mmol/L) }\end{array}$} & $\mathrm{n}$ & 36 & 38 & 37 & 41 \\
\hline & media & 140,1 & 139,7 & 141,3 & 139,9 \\
\hline & desvío estándar & 4,0 & 4,7 & 2,76 & 5,7 \\
\hline & mediana & 140 & 140 & 141 & 140 \\
\hline & mínimo & 132 & 129 & 135 & 130 \\
\hline & máximo & 148 & 151 & 148 & 151 \\
\hline & intervalo de referencia* & $132,2-147,9$ & $130,5-148,9$ & $135,9-146,7$ & $128,8-151,1$ \\
\hline \multirow{7}{*}{$\begin{array}{l}\text { Potasio } \\
\text { (mmol/L) }\end{array}$} & $\mathrm{n}$ & 39 & 39 & 37 & 37 \\
\hline & media & 3,83 & 3,87 & 4,54 & 4,32 \\
\hline & desvío estándar & 0,51 & 0,51 & 0,44 & 0,45 \\
\hline & mediana & 3,80 & 3,80 & 4,50 & 4,30 \\
\hline & mínimo & 2,60 & 2,80 & 3,50 & 3,40 \\
\hline & máximo & 4,60 & 4,81 & 5,20 & 5,50 \\
\hline & intervalo de referencia* & $2,83-4,80$ & $2,87-4,86$ & $3,67-5,40$ & $3,43-5,20$ \\
\hline \multirow{7}{*}{$\begin{array}{l}\text { Hierro } \\
(\mu \mathrm{g} / \mathrm{dL})\end{array}$} & $\mathrm{n}$ & 39 & 39 & 39 & 40 \\
\hline & media & 127,7 & 104 & 119,5 & 127,8 \\
\hline & desvío estándar & 54,1 & 51,7 & 59,3 & 27,8 \\
\hline & mediana & 128,0 & 97,0 & 148,0 & 138 \\
\hline & mínimo & 44,0 & 26,0 & 21,0 & 59 \\
\hline & máximo & 222 & 221,0 & 249,0 & 155,0 \\
\hline & intervalo de referencia* & $21,6-233,8$ & $26,1-205,4$ & $24,5-235,5$ & $67,0-155,0$ \\
\hline \multirow{7}{*}{$\begin{array}{l}\text { Cobre } \\
(\mu \mathrm{g} / \mathrm{dL})\end{array}$} & $\mathrm{n}$ & 38 & 39 & 39 & 40 \\
\hline & media & 0,82 & 0,95 & 0,68 & 1,13 \\
\hline & desvío estándar & 0,21 & 0,20 & 0,09 & 0,36 \\
\hline & mediana & 0,77 & 0,90 & 0,67 & 1,05 \\
\hline & mínimo & 0,52 & 0,62 & 0,49 & 0,09 \\
\hline & máximo & 1,30 & 1,34 & 0,90 & 1,86 \\
\hline & intervalo de referencia* & $0,52-1,30$ & $0,66-1,31$ & $0,50-0,85$ & $0,42-1,83$ \\
\hline \multirow{7}{*}{$\begin{array}{l}\text { Cinc } \\
(\mu g / d L)\end{array}$} & $\mathrm{n}$ & 38 & 37 & 37 & 41 \\
\hline & media & 0,76 & 0,69 & 0,81 & 0,86 \\
\hline & desvío estándar & 0,21 & 0,06 & 0,19 & 0,17 \\
\hline & mediana & 0,69 & 0,69 & 0,79 & 0,84 \\
\hline & mínimo & 0,46 & 0,53 & 0,56 & 0,59 \\
\hline & máximo & 1,27 & 0,80 & 1,28 & 1,24 \\
\hline & intervalo de referencia* & $0,48-1,24$ & $0,57-080$ & $0,43-1,18$ & $0,61-1,22$ \\
\hline
\end{tabular}

* Calculados 
Tabla 1b: Medias, medianas, valores mínimo y máximo, intervalos de referencia, y distribuciones de datos para los distintos minerales en suero para la categoría gestantes $(\mathrm{G})$ y cachorras $(\mathrm{CH})$.

\begin{tabular}{|c|c|c|c|c|c|}
\hline \multirow{3}{*}{ MINERALES } & \multicolumn{5}{|l|}{ Líneas genéticas } \\
\hline & \multirow{2}{*}{ Parámetros y categoría } & \multicolumn{2}{|c|}{$\mathbf{A}$} & \multicolumn{2}{|r|}{ B } \\
\hline & & G & $\mathrm{CH}$ & G & $\mathrm{CH}$ \\
\hline \multirow{7}{*}{$\begin{array}{l}\text { Calcio } \\
\text { (mg/dL) }\end{array}$} & $\mathrm{n}$ & 35 & 35 & 38 & 34 \\
\hline & media & 10,95 & 9,18 & 11,42 & 11,14 \\
\hline & desvío estándar & 1,86 & 1,65 & 1,87 & 1,97 \\
\hline & mediana & 10,65 & 9,01 & 10,97 & 10,51 \\
\hline & mínimo & 8,11 & 6,93 & 9,24 & 7,79 \\
\hline & máximo & 15,20 & 12,36 & 15,52 & 15,96 \\
\hline & intervalo de referencia* & $8,19-14,80$ & $5,94-12,41$ & $9,26-15,45$ & $8,48-15,50$ \\
\hline \multirow{7}{*}{$\begin{array}{l}\text { Fósforo } \\
\text { (mg/dL) }\end{array}$} & $\mathrm{n}$ & 35 & 35 & 38 & 34 \\
\hline & media & 5,60 & 6,79 & 6,81 & 7,70 \\
\hline & desvío estándar & 0,83 & 1,27 & 1,41 & 1,62 \\
\hline & mediana & 5,82 & 6,71 & 6,38 & 8,36 \\
\hline & mínimo & 3,69 & 4,75 & 4,75 & 4,79 \\
\hline & máximo & 6,91 & 9,77 & 9,97 & 9,97 \\
\hline & intervalo de referencia* & $3,98-7,22$ & $4,30-9,28$ & $4,04-9,57$ & $4,95-9,86$ \\
\hline \multirow{7}{*}{$\begin{array}{l}\text { Magnesio } \\
\text { (mg/dL) }\end{array}$} & $\mathrm{n}$ & 35 & 35 & 38 & 34 \\
\hline & media & 1,79 & 2,14 & 2,01 & 2,13 \\
\hline & desvío estándar & 0,30 & 0,52 & 0,42 & 0,62 \\
\hline & mediana & 1,77 & 2,12 & 1,97 & 1,98 \\
\hline & mínimo & 1,33 & 1,27 & 1,34 & 1,17 \\
\hline & máximo & 2,56 & 2,97 & 2,98 & 3,92 \\
\hline & intervalo de referencia* & $1,19-2,38$ & $1,12-3,15$ & $1,19-2,84$ & $0,91-3,34$ \\
\hline \multirow{7}{*}{$\begin{array}{l}\text { Sodio } \\
\text { (mmol/L) }\end{array}$} & $\mathrm{n}$ & 35 & 35 & 35 & 34 \\
\hline & media & 141,4 & 139,6 & 138,6 & 141,2 \\
\hline & desvío estándar & 6,79 & 4,71 & 3,28 & 4,27 \\
\hline & mediana & 141 & 139 & 138 & 141 \\
\hline & mínimo & 130 & 133 & 133 & 131 \\
\hline & máximo & 154 & 153 & 144 & 151 \\
\hline & intervalo de referencia* & $128,1-154,7$ & $130,4-148,9$ & $132,2-145,1$ & $132,8-149,5$ \\
\hline \multirow{7}{*}{$\begin{array}{l}\text { Potasio } \\
\text { (mmol/L) }\end{array}$} & $\mathrm{n}$ & 35 & 35 & 38 & 34 \\
\hline & media & 3,91 & 3,93 & 4,52 & 4,59 \\
\hline & desvío estándar & 0,44 & 0,55 & 0,39 & 0,40 \\
\hline & mediana & 3,80 & 3,90 & 4,70 & 4,60 \\
\hline & mínimo & 3,20 & 2,70 & 3,70 & 3,80 \\
\hline & máximo & 4,90 & 4,87 & 4,90 & 5,20 \\
\hline & intervalo de referencia* & $3,04-4,79$ & $2,85-5,01$ & $3,75-4,90$ & $3,08-5,37$ \\
\hline \multirow{7}{*}{$\begin{array}{l}\text { Hierro } \\
(\mu \mathrm{g} / \mathrm{dL})\end{array}$} & $\mathrm{n}$ & 34 & 35 & 38 & 34 \\
\hline & media & 122,0 & 118,8 & 114,1 & 124,5 \\
\hline & desvío estándar & 37,2 & 34 & 34,2 & 29,9 \\
\hline & mediana & 115 & 117 & 108,0 & 135,0 \\
\hline & mínimo & 66,0 & 54,0 & 55,0 & 54,0 \\
\hline & máximo & 223,0 & 186,0 & 167,0 & 186,0 \\
\hline & intervalo de referencia* & $49,3-195,1$ & $52,2-185,5$ & $58,5-166,0$ & $65,9-183,2$ \\
\hline \multirow{7}{*}{$\begin{array}{l}\text { Cobre } \\
(\mu \mathrm{g} / \mathrm{dL})\end{array}$} & $\mathrm{n}$ & 34 & 35 & 37 & 33 \\
\hline & media & 0,90 & 0,76 & 1,05 & 0,79 \\
\hline & desvío estándar & 0,33 & 0,11 & 0,23 & 0,09 \\
\hline & mediana & 0,72 & 0,79 & 0,99 & 0,78 \\
\hline & mínimo & 0,62 & 0,57 & 0,64 & 0,66 \\
\hline & máximo & 1,67 & 0,92 & 1,52 & 0,99 \\
\hline & intervalo de referencia* & $0,63-1,70$ & $0,57-0,91$ & $0,60-1,50$ & $0,61-0,96$ \\
\hline \multirow{7}{*}{$\begin{array}{l}\text { Cinc } \\
(\mu g / d L)\end{array}$} & $\mathrm{n}$ & 33 & 35 & 36 & 34 \\
\hline & media & 0,88 & 0,88 & 1,07 & 1,16 \\
\hline & desvío estándar & 0,30 & 0,26 & 0,17 & 0,23 \\
\hline & mediana & 0,74 & 0,79 & 1,03 & 1,16 \\
\hline & mínimo & 0,64 & 0,65 & 078 & 0,75 \\
\hline & máximo & 0,83 & 1,86 & 1,59 & 1,57 \\
\hline & intervalo de referencia* & $0,64-1,61$ & $0,65-1,64$ & $0,73-1,40$ & $0,71-1,61$ \\
\hline
\end{tabular}

* Corregido 
En el presente trabajo, los límites inferiores de los intervalos de referencia calculados para el calcio, magnesio, fósforo, sodio, potasio e hierro fueron menores a los mencionados por Klem et al., en animales destetados.

También, se observaron variabilidades en el intervalo de referencia en los minerales $\mathrm{Ca}, \mathrm{Na}, \mathrm{K}, \mathrm{Fe}$ y $\mathrm{Zn}$ de las cerdas gestantes y cachorras. Al comparar el intervalo de referencia calculado para el calcio de las categorías gestantes, cachorras, destetados con genéticas $A$, se observaron diferencias con los publicado por Cooper et al. En el mismo artículo observamos semejante comportamiento al calcio en el fósforo. Los restantes minerales analizados coinciden a lo observado en aquella publicación (Cooper et al 2014).

En general, la línea genética B mostró valores más elevados en las cuatro categorías estudiadas, por lo que la selección de esa línea genética se adapta mejor al sistema de producción intensivo.

Analizando los resultados de agua, las variables cloruro, sulfato, nitrato, fluoruro, calcio, magnesio, sodio, dureza total, alcalinidad y conductividad se observaron distintas en las dos líneas genéticas. Los valores de $\mathrm{pH}$ se encontraron dentro del rango considerado aceptable para el consumo de cerdos. Los promedio de las variables del análisis fisicoquímico y bacteriológico de los establecimientos con genética $A$ y $B$, se encontraron dentro de los valores de referencia mencionados por diferentes autores. La dureza mayor a 250 ppm indica que es posible que el animal obtenga a través del agua de bebida el requerimiento de magnesio, y por eso es importante comprobar la relación Ca:Mg de la dieta (Spiner, 2009). El valor medio del pH en el agua depende de la composición mineral del suelo, es por ello que en los establecimientos de cada genética los valores fueron diferentes (Pilatti et al. 2003).

Todos los parámetros fisicoquímicos del agua se encontraban dentro de los límites informados por la Organización Mundial para la Salud (OMS) en ambas líneas genéticas. Con las variables analizadas del agua se puede decir que son aptas para consumo. En posteriores ensayos se podrían evaluar otros minerales para descartar posibles interferencias con otros componentes de la dieta.

Para descartar la influencia de la composición mineral de los alimentos sobre las variaciones observadas en ésta publicación (datos no publicados), se deberá realizar el análisis de cada uno de los componentes de la dieta por separado. En el proyecto de investigación CAI+D 2016 se difundirá la composición nutricional de los alimentos y se analizará su efecto en la producción porcina, al ensayar distintas fuentes minerales.

Los resultados de nuestro trabajo de investigación, permitirán establecer los intervalos de referencia de macrominerales y microminerales de las categorías recién nacido, destetados, cachorras y cerdas gestantes para la producción porcina regional en sistemas intensivos.

Podemos concluir que los intervalos de referencia calculados en la presente investigación serán útiles para el diagnóstico de posibles deficiencias mineral y para la vigilancia nutricional en cerdo de producción de carne.

\section{Agradecimientos}

Los autores agradecen a la profesora Luciana Cignetti de la asignatura Inglés por la revisión del Summary, al Dr. Gustavo Ribero por la asistencia en el manejo del equipo de absorción atómica perteneciente al Laboratorio Central de la Facultad de Ciencias Agrarias de la Universidad Nacional del Litoral, a la Mg. Dafna Eluk por la colaboración en la presentación del artículo. También hacemos mención y reconocimiento al Cientibecario del Programa de Becas de Iniciación a la Investigación para estudiantes de carreras de grado Federico $\mathrm{S}$. Pighin; a los estudiantes integrantes del Proyecto CAI+D Cecilia Manni, Santiago Von der Thousen y a la responsable colaboración de los alumnos del Grupo de Estudio Dirigido de porcinos de la FCV-UNL quienes participaron del manejo y obtención de las muestras en los viajes a cada uno de los establecimientos.

La publicación se pudo realizar gracias al financiamiento del Proyecto CAI+D 2011: “Evaluación del perfil mineral y hematológico en distintos grupos etarios de cerdos en granjas bajo sistemas productivos intensivos de las provincias de Santa Fe y Entre Ríos" perteneciente a la directora Dra Viviana. P. Roldán docente-investigadora de la FCV - UNL.

\section{Bibliografía}

AOAC, Association of Official Analytical Chemist. 2005. Official Methods of Analysis of the Association of Analytical Chemists International, 18th ed. Gathersburg, MD U.S.A, 117 pp.

Campagna D. 2005. Caracterización de los principales componentes de los sistemas de producción de cerdos a campo en Argentina. III Encuentro latinoamericano de especialistas en sistemas de producción porcina a campo. INTA Marcos Juarez, Agosto 2005. pp.1-5.

Cooper CA, Moraes LE, Murray JD, Owens SD. 2014. Hematologic and biochemical reference intervals for specific pathogen free 6-week-old Hampshire-Yorkshire crossbred pigs. J. Anim. Sci. Biotechnol. 5:5, 1891-2049.

Crenshaw TD, Schneider DK, Carlson CS, Parker JB, Sonderman JP, Ward TL, Wilson ME. 2013. Tissue mineral concentrations and osteochondrosis lesions in prolific sows across parities 0 through 7. J. Anim. Sci. 91: 1255-1269.

Duan QW, Li JT, Gong LM, Wu H, Zhang LY. 2013. Effects of graded levels of montmorillonite on performance, hematological parameters and bone mineralization in weaned pigs. Asian Australas. J. Anim. Sci. 26: 1614-1621. 
FAO 2013. Food Outlook. Bianual Report on Global Markets. Digital edition, Ed. by FAO, Roma, Italia. 140 pp.

García González MC. 2009. Consumo de agua y estrategias de ahorro en la ganadería porcina. Albéitar PV (publicación en línea). http://albeitar.portalveterinaria.com

García S. 2006. FODA del Sector Porcino argentino. Asociación Argentina de Productores Porcinos 795:18-24.

Klem TB, Bleken E, Morberg H, Thoresen SI, Framstad T. 2010. Hematologic and biochemical reference intervals for Norwegian crossbreed grower pigs. Vet. Clin. Pathol. 39: 221226.

Mahan D, 2006. Necesidades de minerales en cerdos seleccionados por un alto contenido en magro y cerdas de alta productividad. Avance en nutrición y alimentación animal. XXII curso de especialización FEDNA; Barcelona. España; 125-142

Muñiz, M, Berto D, Wechsler, F, Passos, AA, Lima GJ. 2005. Chelated minerals in diets for weaned piglets. J. Anim. Sci. 83: 178.

NRC, National Research Council. 2012. Nutrient Requirements of Swine. Eleventh Revised Edition. National Academic Press, Washington DC, USA. pp 74 - 88.

Peng CC, Yan JY, Dong B, Zhu L, Tian YY, Gong LM. 2016. Effects of graded levels of cupric citrate on growth performance, antioxidant status, serum lipid metabolites and immunity and tissue residues of trace elements in weaned pigs. Asian Australas. J. Anim. Sci. 30: 538-545.

Pilatti MA, Orellana JA, Felli OM. 2003. The ideal soil: III fitness of edadhic variable to achieve sustenance in agroecosystems. J. Sust. Agric. 109-132.

Spiner N. 2009. Calidad de agua de bebida para cerdos. INTA EEA Marcos Juárez. www.3tres3.com/nutricion/calidad-delagua-para-cerdos 2694 .

Yague AP. 2007. Directorio de los minerales en alimentación porcina. Avances en Tecnología Porcina 4: 20-34. 